\title{
Risk factors for cervical cancer among HPV positive women in Mexico
}

\author{
Yvonne N Flores, PhD( ${ }^{(1)}$ David M Bishai, MD, (2) KeertiV Shah, MD, (3) Eduardo Lazcano-Ponce, D en C, ${ }^{(4)}$ \\ Attila Lörincz, MD, (5) Mauricio Hernández, PhD, (4) Daron Ferris, MD, ${ }^{(6)}$ Jorge Salmerón, D en C(1)
}

\begin{abstract}
Flores YN, Bishai DM, Shah KV, Lazcano-Ponce E, Lörincz A, Hernández M, Ferris D, Salmerón J. Risk factors for cervical cancer among HPV positive women in Mexico. Salud Publica Mex 2008;50:49-58.
\end{abstract}

\begin{abstract}
Objective. To identify factors that are associated with an increased risk of developing high-grade cervical intraepithelial neoplasia $(\mathrm{CIN})$ or cancer among human papillomavirus (HPV)-positive women in Mexico. Material and Methods. A case-control study design was used. A total of 94 cases and $50 \mathrm{I}$ controls who met the study inclusion criteria were selected from the 7732 women who participated in the Morelos HPV Study from May 1999 to June 2000. Risk factor information was obtained from interviews and from HPV viral load results. Odds ratios and 95 percent confidence intervals were estimated using unconditional multivariate regression. Results. Increasing age, high viral load, a young age at first sexual intercourse, and a low socio-economic status are associated with an increased risk of disease among HPV-positive women. Conclusions. These results could have important implications for future screening activities in Mexico and other low resource countries.
\end{abstract}

Key words: cervical cancer, HPV, risk factors, screening, Mexico
Flores YN, Bishai DM, Shah KV, Lazcano-Ponce E, Lörincz A, Hernández M, Ferris D, Salmerón J.

Factores de riesgo de cáncer cervical

en mujeres VPH positivas en México.

Salud Publica Mex 2008;50:49-58.

\section{Resumen}

Objetivo. Identificar factores asociados con un mayor riesgo de desarrollar neoplasia intraepitelial cervical (NIC) de alto grado o cáncer en mujeres con virus de papiloma humano (VPH), en México. Material y métodos. Se utilizó un diseño de casos y controles. Un total de 94 casos y 50 I controles fueron seleccionados de las 7732 mujeres que participaron en el Estudio de VPH en Morelos, de mayo de 1999 a junio de 2000. La información sobre factores de riesgo se obtuvo de entrevistas y de los resultados de carga virales de VPH. Se estimaron razones de momios e intervalos de confianza de $95 \%$ con modelos multivariados de regresión no condicionada. Resultados. El incremento de edad, la carga viral elevada, la edad temprana al inicio de la vida sexual y el nivel socioeconómico bajo se asocian con un mayor riesgo de enfermedad en mujeres VPH positivas. Conclusiones. Estos resultados podrían tener implicaciones importantes a futuro para las actividades de tamizaje en México y en otros países de bajos recursos.

Palabras clave: cáncer cervical, VPH, factores de riesgo, tamizaje, México

(I) Unidad de Investigación Epidemiológica y en Servicios de Salud, Instituto Mexicano del Seguro Social, Morelos, México.

(2) Department of Population and Family Health Sciences, Johns Hopkins University, Bloomberg School of Public Health, Baltimore

(3) Department of Molecular Microbiology and Immunology, Johns Hopkins University, Bloomberg School of Public Health, Baltimore.

(4) Centro de Investigación en Salud Poblacional, Instituto Nacional de Salud Pública, Morelos, México.

(5) Digene Corporation, Gaithersburg, Maryland.

(6) Medical College of Georgia,Augusta, Georgia.

Received on: June 6,2007 • Accepted on: October 26, 2007

Address reprint requests to: Dra.Yvonne Flores. Unidad de Investigación Epidemiológica y en Servicios de Salud, Instituto Mexicano del Seguro Social.Av. Plan de Ayala esq. Central s/n. 62450 Cuernavaca, Morelos, México. E-mail:yflores@jhsph.edu 
$\mathrm{A}$ though a national screening program has existed since 1974, cervical cancer remains a leading cause of death for women in Mexico. The incidence and mortality estimates for cervical cancer in Mexico in 2000 were 40.5 and 17.1, respectively. In 2000, an estimated 6650 women died from cervical cancer in Mexico, the second highest number in Latin America after Brazil. ${ }^{1}$ The high incidence and mortality rates of late-stage cervical cancer can be considered indirect evidence of the low impact of the Mexican National Cervical Cancer Screening Program.

The recognition of human papillomavirus (HPV) infection as a necessary cause of cervical cancer ${ }^{2,3}$ has increased the use of HPV diagnostic tests for screening activities. However, most women who receive a positive $\mathrm{HPV}$ test result do not go on to develop high-grade cervical intraepithelial neoplasia (CIN) or cervical cancer. Thus, determining which factors may be associated with high-grade CIN for women who are high-risk HPV DNA positive is important, so that limited colposcopy and treatment services can be used most efficiently. Estimates of the prevalence of HPV infection vary greatly (between $2 \%$ and $44 \%$ ) around the world, ${ }^{4,5}$ so the factors that contribute to the rare occurrence of cervical cancer after HPV infection might also differ from country to country. One of the objectives of the Morelos HPV Study 6,7 was to investigate the role of HPV infection and other co-factors for the risk of developing high-grade CIN or cervical cancer among a sample of Mexican women.

Certain factors that were once thought to be associated with an increased risk of cervical cancer are now considered to be risk factors for HPV infection. Some of these factors include a woman's age at first sexual intercourse and number of lifetime sexual partners. ${ }^{8-10}$ These factors can now be examined to determine their association with progression to high-grade CIN and cancer among HPV positive women. Behavioral factors such as reproductive history and exposure to hormones, ${ }^{11-14}$ as well as smoking ${ }^{15-17}$ have also been associated with an increased risk of cervical cancer in some studies. Other factors such as history of use of cervical cancer screening services and lower socio-economic status, as defined by income and education, have also been associated with cervical cancer risk. ${ }^{18,19}$ A high HPV viral load has previously been identified as a risk factor for the progression to CIN and cervical cancer, ${ }^{20-23}$ although other studies have not found this association. ${ }^{24,25}$

Since an HPV infection is necessary for the development of cervical cancer, more recent case-control studies have examined these risk factors by comparing HPV-positive cases to HPV-positive controls. ${ }^{26-28}$ This has been done to differentiate the effects of these factors as promoters of HPV infection, from their participation in the progression of an HPV infection to cervical cancer. However, the role of other factors besides the presence of a high-risk HPV infection for the development of high-grade CIN or cancer has still not been completely determined. Examining the role of HPV co-factors in different populations is important to determine if these factors are universal and etiologic.

We compared high-risk HPV infected cases to high-risk HPV infected controls to examine the association between additional risk factors -such as age, viral load, age at first sexual intercourse, number of sexual partners, parity, and socio-economic status- and risk of developing high-grade CIN or cancer. The purpose of this type of analysis is to find ways to identify which HPV-positive women may have an increased risk of developing disease. In low-resource countries such as Mexico, screening and treatment facilities should focus on reaching women who are at greatest risk of having treatable lesions, to prevent the occurrence of incurable invasive cancer. $^{29}$

\section{Materials and Methods}

Population. A case-control study design was used to assess co-factors among a sample of women aged 20 to 80 attending cervical cancer screening services at IMSS clinics in Morelos, Mexico from May 1999 to June 2000. This study was nested within a fixed cohort of women who participated in the Morelos HPV Study (total baseline population=7 732) (figure 1). The design and methods of this study are described elsewhere and the ethical committees at the participating institutions approved the study protocol and consent forms for this study. ${ }^{6,7}$ Subjects entered the study after providing signed informed consent.

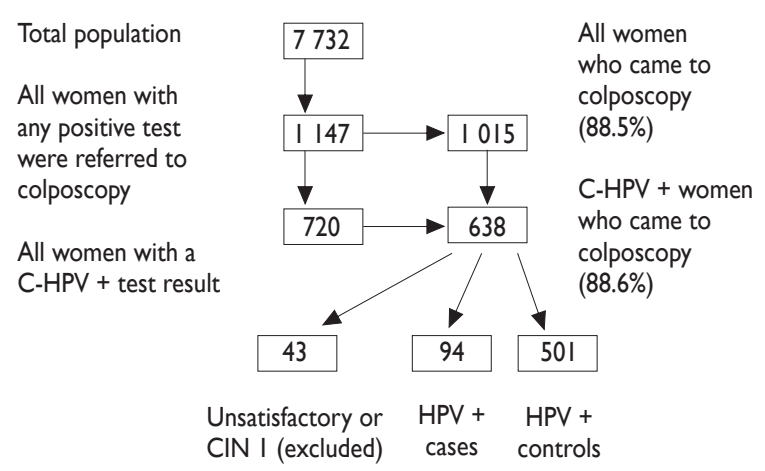

Figure I. Case-control study population 
All of the participating women provided a self-collected vaginal specimen and a clinician also obtained a separate cervical specimen during the pelvic examination. The Digene Hybrid Capture 2 (HC2) test (Digene Corporation, MD) was used to detect high-risk HPV DNA in the separate vaginal and cervical samples. A total of 1147 women who had at least one positive Pap, self- or clinician-collected HPV test result were asked to return for a colposcopy evaluation. Women with a Pap result of ASCUS or worse were referred to colposcopy.

The case-control study subjects were selected from the 720 study participants who were HPV-positive as detected by the HC2 test using clinician-collected cervical specimens, and had a colposcopic evaluation $(n=638)$. The $82 \mathrm{HPV}$-positive women who did not receive a colposcopic evaluation were excluded from this study. A total of 94 cases and 501 controls were selected from the 638 women who met the study inclusion criteria; 43 HPV-positive women were excluded from the study population because they had a low-grade CIN diagnosis or an unsatisfactory histology result (figure 1). The 638 women who met the study inclusion criteria do not differ statistically from the 720 women in terms of age, viral load, age at first sexual intercourse, number of births, and number of pregnancies.

Cases were defined as women between the ages of 20 to 80 , who were HPV-positive, as detected by the HC2 test using clinician-collected cervical specimens, with a histologically confirmed diagnosis of high-grade CIN or cervical cancer during the specified screening period. A total of seven women were diagnosed as having CIN 2, 75 women were diagnosed with CIN 3, and 12 women were diagnosed with cervical cancer. Controls were defined as women aged 20 to 80 who were HPV-positive, as detected by the $\mathrm{HC} 2$ test, without a histologic diagnosis of low-grade CIN or worse during the specified screening period. The $94 \mathrm{HPV}$-positive cases represent 93\% (94/101) of all the high-grade CIN and cervical cancer cases that were detected at baseline in the Morelos HPV Study. The $501 \mathrm{HPV}$-positive controls represent 100\% of the colposcopically confirmed HPV-positive women without disease.

All lesions observed during the colposcopic evaluations were biopsied, and in some cases an endocervical curetage was performed when the examination was not satisfactory. A careful examination during colposcopy helped to ensure that the determination and confirmation of a disease outcome was as accurate as possible. Histopathology results were used for diagnosis in order to reduce misclassification of disease. Three pathologists who received standardized training prior to their participation in this study were employed to determine the diagnoses in an individual and blind manner.
Data Collection and Instruments. Women who received a positive HPV diagnosis were interviewed to obtain information about their potential risk factors. The following data were collected (1) demographic data, (2) reproductive and sexual histories, (3) risk factors for HPV and cervical cancer, and (4) past use of the cervical cancer screening program. The information about cervical cancer risk factors for the cases and controls was obtained in a similar fashion. The cases and controls were interviewed by trained personnel during their follow-up visit at the colposcopy clinic. The data collection instruments were pilot-tested using in-depth cognitive interview techniques.

Measurement of Variables. Self-reported risk factors and viral load results were evaluated in categories that were used to determine different risk classifications for highgrade CIN and cervical cancer. Variables were chosen based on the existing literature and on the possibility of using specific risk categories to triage women as part of an HPV-based screening program. The age categories we used are: (1) less than 30 vs. 30+; and (2) less than 24 vs. 25-34, 35-44, 45-54, and 55+. The HC2 RLU/PC ratio results were used as a semi-quantitative measure of viral burden. The tertile distribution of the viral load results was used to create three categories of log-transformed viral load: (1) low, (2) medium, and (3) high. Age at first sexual intercourse was examined using three groups: (1) less than 16, (2) 16-19, and (3) aged 20 and older. The respondent's number of lifetime partners was also modeled as a categorical variable, using two groups: 1-2 partners vs. 3 or more.

The following socio-demographic variables were included in the analysis: (1) socio-economic status (SES), (2) area of residence, (3) level of education, and (4) marital status. A SES index was created by dividing the total household monthly income by the reported number of dependents. Area of residence was examined as a categorical variable with two groups: urban and semi-urban. Education level (less than high school vs. high school or greater) and marital status (married/ consensual union, partner, single) were also modeled as categorical variables.

Number of pregnancies, live births, and cesarean deliveries were modeled as categorical variables. Additionally, a variable was constructed to indicate the proportion of vaginal deliveries vs. cesareans, which was divided in two categories: mostly vaginal deliveries $(>50 \%)$ and mostly cesarean deliveries $(>50 \%)$. Use of hormonal contraceptives was also examined. This variable was modeled using the groups: (1) no use, (2) $<5$ years of use, and (3) 5+ years of use. Smoking was also examined by the following categories of years smoked: (1) none, $(2)<10$ years, and (3) $10+$ years. The 
total number of lifetime Pap tests was evaluated to determine the use of cervical cancer screening services and was also modeled as a categorical variable: (1) five or more lifetime Paps vs. (2) less than five.

Statistical Methods. Odds ratios (OR) and 95\% confidence intervals $(C I)$ were estimated from unconditional multivariate regression models to determine which factors are associated with an increased risk of high-grade CIN or cervical cancer. A first analysis was performed using multivariate regression to determine the association between the independent variables and risk of high-grade CIN or cervical cancer, after adjusting for age, viral load, and age at first sexual intercourse (model 1, table I). A second analysis was performed using an unconditional multivariate regression model that included the main independent variables: age, viral load and age at first sexual intercourse, as well as other potential confounders (model 2, table I). Some of the cases and controls had missing data for the following variables: number of lifetime sexual partners, income, number of dependents, level of education, marital status, use of hormones, smoking, and lifetime number of Paps. A missing category was created and used in our adjustment analysis.

The ORs obtained from the logistic coefficients of age, viral load, and age at first sexual intercourse were used to estimate the population attributable fractions (PAFs) of these factors. The PAFs indicate the proportion by which the incidence rate of the outcome in the entire population would be reduced if the exposure(s) were eliminated. ${ }^{30}$ FoxPro 2.6 for Windows was used for data management and Stata 9.0 was used for the statistical analysis.

\section{Results}

The high-grade CIN and cervical cancer cases were, on average, a year and a half younger than the controls (median age $=39.5$ for cases and 41 for controls). More than $87 \%$ of the cases in this study occurred among women aged 30 years or older. The results of our bivariate analysis of age show that risk of high-grade CIN or cervical cancer was almost five times greater for women between the ages of 25-34 (95\% CI=1.1-21.7), and nearly six times higher for women aged 35-44 (95\% Cl=1.3-25.6), as compared to women under the age of 25 . For women 45-54 years old the risk of high-grade CIN or cervical cancer was 4.5 times greater $(95 \% C I=1.0-20.2)$ than for women under 25 . Women over age 55 had a 3.5 greater risk (95\% CI=0.78-15.6) than women under 25 (data not shown). After adjusting for viral load and age at first sexual intercourse (AFSI), the OR of high-grade
CIN or cancer was 1.85 (95\% CI=0.96-3.6) for women 30 or older as compared to women under age 30 (model 1 , table I).

Table I shows the results of two multivariate analyses which examined the association between several risk factors for high-grade CIN and cervical cancer. Model 1 indicates the relative risk of high-grade CIN and cervical cancer for selected covariates after adjusting for age, viral load and AFSI. Model 2 shows the relative risk associated with each variable of interest after adjusting for age, viral load, AFSI, number of lifetime sexual partners, SES, education level, area of residence, marital status, number of live births, use of hormonal contraceptives, smoking, and number of lifetime Paps. Both models indicate a positive association between increasing HPV viral load and risk of high-grade CIN or cancer. Women with a medium viral load had a significantly greater risk of high-grade CIN or cancer as compared to women with a low viral load $(O R=3.26$; $95 \% C I=1.2-9.2)$. The risk of disease was also greater for women with a high viral load $(O R=5.50 ; 95 \% C I=2.3-13.6)$ than for women who have a low viral load (model 2, table I). Additionally, approximately $6 \%$ of the cases in this study had a low viral load ( $<2.55 \log$ RLUs), whereas $27 \%$ of the controls had a low viral load diagnosis.

Both multivariate models also indicate that older AFSI was significantly associated with a decreased risk of high-grade CIN or cancer. Women whose AFSI was between the ages of 16-19 had an OR of 0.49 (95\% $C I=0.28-0.87)$ as compared to women who had sexual intercourse for the first time before the age of 16 . Women who began to have sexual intercourse after the age of 20 had an OR of 0.42 (95\% CI=0.22-0.78), as compared to the reference group (model 1, table I). After adjusting for the other covariates in model 2 , the protective association between risk of high-grade CIN or cancer and an AFSI of 20 or greater was still found to be significant $(O R=$ 0.43 ; 95\% CI=0.20-0.91) (model 2, table I). The average AFSI for the total study population of 732 was found to be age 19, while the AFSI for the clinician-collected HPV-positive sample was age 18.

Having three or more lifetime sexual partners was not significantly associated with risk of high-grade CIN or cancer in either of the multivariate models. A statistically significant protective association was observed for high SES (OR=0.52, 95\% CI=0.29-0.94) as compared to low SES in model 2. After controlling for age, viral load, and AFSI in model 1, and after adjusting for the other covariates included in model 2, no statistically significant association was found between education level, area of residence, marital status, and risk of highgrade CIN or cancer. 
Table I

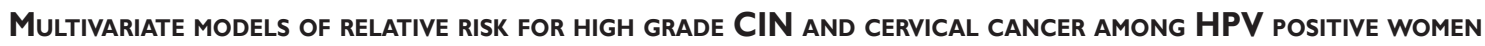

\begin{tabular}{|c|c|c|c|c|c|c|}
\hline & $\begin{array}{l}\text { Cases } \\
n(\%)\end{array}$ & $\begin{array}{c}\text { Controls } \\
n(\%)\end{array}$ & Model I* & & & Model $2^{\ddagger}$ \\
\hline isk Factor & $(n=94)$ & $(n=501)$ & $95 \% \mathrm{Cl}$ & $p$-value & ORa & $95 \% \mathrm{Cl}$ \\
\hline
\end{tabular}

Age(years)

\begin{tabular}{|c|c|c|c|c|c|c|c|c|}
\hline$<30$ & $12(12.8)$ & III (22.2) & $1.00 \S$ & & & 1.00 & & \\
\hline $30+$ & $82(87.2)$ & $390(77.8)$ & $1.85 \S$ & {$[0.96-3.6]$} & 0.065 & 1.65 & {$[0.75-3.6]$} & 0.214 \\
\hline
\end{tabular}

Viral factors

HPV log transformed viral load

\begin{tabular}{|c|c|c|c|c|c|c|c|c|}
\hline Low $(<2.55)$ & $6 \quad(6.4)$ & $133(26.5)$ & $1.00^{\#}$ & & & 1.00 & & \\
\hline Medium (2.56-3.9) & $16(17)$ & $92(18.4)$ & $3.8 I^{\#}$ & [I.4-10.2] & 0.008 & 3.26 & [1.2-9.2] & 0.026 \\
\hline High (>3.92) & $72(76.6)$ & $276(55.1)$ & $5.79^{\#}$ & {$[2.4-13.7]$} & 0.000 & 5.50 & {$[2.3-13.5]$} & 0.000 \\
\hline
\end{tabular}

Risk factors for HPV infection

Age at first sexual intercourse (years)

\begin{tabular}{|c|c|c|c|c|c|c|c|c|}
\hline$<16$ & $26(27.7)$ & $74(14.8)$ & $1.00^{\&}$ & & & 1.00 & & \\
\hline $16-19$ & 43 (45.7) & $250(49.9)$ & $0.49 \&$ & [0.28-0.87] & 0.015 & 0.56 & [0.30-I.04] & 0.067 \\
\hline $20+$ & $25(26.6)$ & I77 (35.3) & $0.42^{\&}$ & {$[0.22-0.78]$} & 0.006 & 0.43 & [0.20-0.9I] & 0.028 \\
\hline
\end{tabular}

Number of lifetime sexual partners

\begin{tabular}{|c|c|c|c|c|c|c|c|c|}
\hline $\mid-2$ & $64(68.1)$ & $316(63.1)$ & 1.00 & & & 1.00 & & \\
\hline $3+$ & 21 (22.3) & 84 (16.8) & 1.21 & {$[0.68-2.2]$} & 0.513 & 1.26 & {$[0.65-2.4]$} & 0.494 \\
\hline
\end{tabular}

Socio-demographic factors

Socio-economic status (pesos/mo./person)

\begin{tabular}{|c|c|c|c|c|c|c|c|c|}
\hline Low $(<\$ 567)$ & $54(57.4)$ & 198 (39.5) & 1.00 & & & 1.00 & & \\
\hline Middle/High $(\$ 568+)$ & $31(33.0)$ & $202(40.3)$ & 0.62 & [0.38-I.0] & 0.062 & 0.52 & {$[0.29-0.94]$} & 0.029 \\
\hline Missing $(n=\mid 10)$ & $9 \quad(9.6)$ & I0I (20.I) & & & & & & \\
\hline
\end{tabular}

Education level (years)

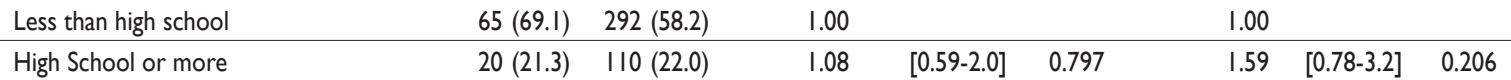

$\begin{array}{lrr}\text { High School or more } & 20(21.3) & 110(22.0) \\ \text { Missing }(n=108) & 9 & (9.6)\end{array}$

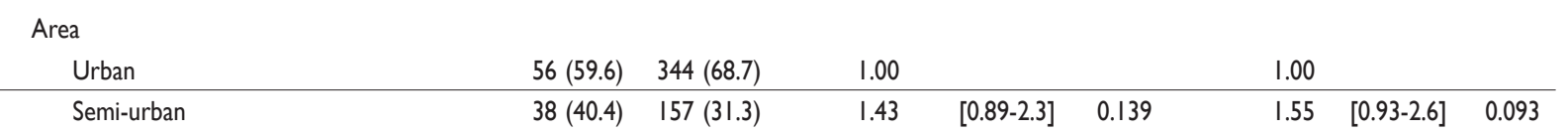

Marital status

\begin{tabular}{|c|c|c|c|c|c|c|c|c|}
\hline Married/consentual union & $57(60.6)$ & $258(5 \mathrm{I} .5)$ & 1.00 & & & 1.00 & & \\
\hline Partner & $7 \quad(7.5)$ & $35 \quad(7.0)$ & 1.02 & {$[0.42-2.5]$} & 0.973 & 1.13 & {$[0.40-3.2]$} & 0.823 \\
\hline No partner & $21(22.3)$ & $94(18.8)$ & 1.02 & {$[0.58-1.8]$} & 0.936 & 1.25 & {$[0.69-2.3]$} & 0.483 \\
\hline Missing $(n=123)$ & $9(9.6)$ & 114 (22.7) & & & & & & \\
\hline
\end{tabular}

(Continues) 
Table I

(Continuation)

Risk Factor

Cases Controls

\section{$n(\%)$}

$(n=50 l)$

$O R^{*}$

Model I*

95\% Cl p-value

Model $2^{\ddagger}$

$95 \% \mathrm{Cl}$-value

Behavioral factors

Number of pregnancies

\begin{tabular}{rrrrrrr} 
& & & & & & \\
$0-1$ & $8(8.5)$ & $84(16.8)$ & 1.00 & & \\
\hline $2-3$ & $25(26.6)$ & $150(29.9)$ & 1.28 & {$[0.53-3.1]$} & 0.583 & \\
\hline $4-5$ & $26(27.7)$ & $120(24.0)$ & 1.41 & {$[0.54-3.7]$} & 0.483 & \\
\hline $6+$ & $35(37.2)$ & $147(29.3)$ & 1.37 & {$[0.51-3.7]$} & 0.529
\end{tabular}

Number of live births

\begin{tabular}{|c|c|c|c|c|c|c|c|c|}
\hline $0-1$ & I4 (I4.9) & |4| (28.I) & 1.00 & & & 1.00 & & \\
\hline $2-3$ & $32(34.0)$ & 161 (32.I) & 1.62 & {$[0.79-3.3]$} & 0.189 & 1.41 & {$[0.66-3.0]$} & 0.379 \\
\hline $4-5$ & $25(26.6)$ & $89(17.8)$ & 2.10 & {$[0.94-4.7]$} & 0.069 & 1.85 & {$[0.78-4.4]$} & 0.163 \\
\hline $6+$ & $23(24.5)$ & II 0 (22.0) & I.4I & {$[0.6 \mid-3.3]$} & 0.418 & 1.33 & [0.54-3.3] & 0.532 \\
\hline
\end{tabular}

Proportion of vaginal births/cesarians ${ }^{\ddagger}$

\begin{tabular}{lrrrrrr} 
Less vaginal, more c-section & 5 & $(5.6)$ & $58(11.6)$ & 1.00 & & \\
\hline More vaginal, less c-section & $89(94.4)$ & $443(88.4)$ & 1.73 & {$[0.64-4.7]$} & 0.279
\end{tabular}

Use of hormonal contraceptives

\begin{tabular}{|c|c|c|c|c|c|c|c|c|}
\hline No use & $36(38.3)$ & $182(36.3)$ & 1.00 & & & 1.00 & & \\
\hline Less than 5 years & $35(37.2)$ & $180(35.9)$ & 0.97 & [0.58-I.7] & 0.922 & 0.93 & [0.53-I.6] & 0.802 \\
\hline 5 years or more & $9 \quad(9.6)$ & $38 \quad(7.6)$ & 1.26 & {$[0.54-2.9]$} & 0.593 & 1.20 & {$[0.49-2.9]$} & 0.689 \\
\hline Missing $(n=115)$ & $14(14.9)$ & I0I (20.2) & & & & & & \\
\hline
\end{tabular}

Smoking

\begin{tabular}{|c|c|c|c|c|c|c|c|c|}
\hline Never & $62(66.0)$ & $307(61.3)$ & 1.00 & & & 1.00 & & \\
\hline Less than 10 years & $5(5.3)$ & $49 \quad(9.8)$ & 0.50 & [0.19-1.3] & 0.161 & 0.42 & {$[0.15-1.2]$} & 0.097 \\
\hline 10 years or more & $12(12.8)$ & $43 \quad(8.6)$ & 1.18 & {$[0.57-2.4]$} & 0.662 & 1.28 & {$[0.59-2.8]$} & 0.529 \\
\hline Missing $(n=103)$ & I (I5.9) & $102(20.3)$ & & & & & & \\
\hline
\end{tabular}

Number of lifetime Paps

\begin{tabular}{|c|c|c|c|c|c|c|c|c|}
\hline 5 or more & $42(44.7)$ & $243(48.5)$ & 1.00 & & & 1.00 & & \\
\hline Less than 5 & $42(44.7)$ & $158(31.5)$ & 1.58 & {$[0.95-2.6]$} & 0.078 & 1.55 & {$[0.91-2.7]$} & 0.110 \\
\hline Missing $(n=110)$ & $10(10.6)$ & $100(20.0)$ & & & & & & \\
\hline
\end{tabular}

* Adjusted for age, viral load, and age at first sexual intercourse (AFSI)

\# Variables included in the model: age, viral load,AFSI, number of lifetime sexual partners, SES, education level, area of residence, marital status, number of live births, use of hormonal contraceptives, smoking, and number of lifetime Paps

$\S$ Adjusted for AFSI and viral load

\# Adjusted for AFSI and age

\& Adjusted for age and viral load

$\neq \mathrm{n}=549$ (495 controls, 90 cases)

Increasing number of pregnancies and live births, as well as type of delivery were not significantly associated with high-grade CIN and cancer, after adjusting for age, viral load and AFSI. After controlling for the covariates included in model 2, a non-significant positive associa- tion was found for having a greater number of live births and risk of high-grade CIN or cancer. The results of the multivariate analysis indicate that having more vaginal deliveries may be associated with an increased risk of high-grade CIN and cancer, as compared to having 
mostly cesarean deliveries. However, this association was not statistically significant (model 1, table I).

In both models, a non-significant protective association was observed for use of oral or injectable contraception for less than five years, as compared to no use. Likewise, a non-significant association was found for the use of hormonal contraception for five years or more and risk of disease. After controlling for age, viral load, and AFSI in model 1 , and after adjusting for the other covariates included in model 2, no statistically significant association was found between smoking and increased risk of high-grade CIN or cancer. A nonsignificant association was found for having less than five lifetime Paps, as compared to five or more and risk of disease in both models (table I).

The ORs for age, viral load, and AFSI were transformed into population-attributable fractions (PAFs). This was done to estimate the fraction of high-grade CIN and cancer cases that can be attributed to other exposures besides infection with HPV. In women who are HPV-positive, 47\% (95\% CI=4-70) of the high-grade $\mathrm{CIN}$ and cancer cases can be attributed to being 30 or older, 58\% (95\% CI=42-70) to having a high viral load (3.92+), and $14 \%$ (95\% CI=0-29) to an AFSI of less than 16. The combined effect of having a high viral load and being 30 or older accounts for $67 \%$ ( $95 \%$ CI=0-90) of the high-grade $\mathrm{CIN}$ and cancer cases. Having a high viral load, being 30 or older, and/or having sexual intercourse for the first time before age 16, accounts for $88 \%$ of the cases (95\% CI=13-98) (table II).

\section{Discussion}

This is the first study that examines which co-factors are associated with an increased risk of high-grade CIN or cancer among high-risk HPV-positive cases and controls in Mexico. Our findings indicate that increasing age, high viral load, low SES, and a young age at first sexual intercourse (AFSI) are associated with an increased risk of disease among HPV-positive women. Other factors such as number of sexual partners, multiparity, use of hormonal contraception, and smoking were not significantly associated with an increased risk of high-grade CIN or cancer in this population.

Our results support the fact that increasing age is one of the principal risk factors for cervical cancer. Invasive cervical cancer arises over many years, even decades, with a peak or plateau in risk around 35-55 years of age. ${ }^{31}$ Studies have also reported that women with a lower SES (as defined by income and education) are at greater risk of infection with HPV and development of cervical cancer. ${ }^{32-34}$ Our viral load results concur with several recent studies which conclude that a high viral load for most high-risk HPV genotypes is associated with prevalent cervical cancer precursors and the development of incident disease. . $^{35,36}$

The population attributable fraction (PAF) analysis also identified that being 30 years or older, having a high viral load (>3.92), and having sexual intercourse for the first time before the age of 16 are significant risk factors for the development of high-grade CIN and cancer among HPV-positive women. Of the $94 \mathrm{HPV}$ positive cases of high-grade CIN and cancer that were evaluated in this study, 91 were identified as having a high viral load and/or being 30 years or older (96.8\%). A total of 93 cases were identified as having a high viral load and/or being 30 years or older and/or having sexual intercourse before the age of 16 (98.9\%). These PAF results support the main findings of this study, which indicate that increasing age, a high viral load, and an

Table II

Proportion of high-grade CiN and cervical cancer cases attributed to age, Viral load (VL), AND AGE AT FIRST INTERCOURSE (AFSI)

\begin{tabular}{|c|c|c|c|c|}
\hline Exposure & $\%$ Exposed & No. Cases & $\begin{array}{c}\text { OR } \\
(95 \% \mathrm{Cl})^{*}\end{array}$ & $\begin{array}{c}\text { Population Attributable } \\
\text { Fraction }(95 \% \mathrm{Cl})^{\ddagger}\end{array}$ \\
\hline Age $30+$ & $79 \%$ & 2 & $2.1 \quad(1.1-4.1)$ & $47 \%(4-70)$ \\
\hline High VL (>3.92) & $40 \%$ & 61 & $3.51(2.2-5.6)$ & $58 \%(42-70)$ \\
\hline AFSI $<16$ & $17 \%$ & 26 & $2.11(1.2-3.6)$ & $14 \%(0-29)$ \\
\hline Age $30+$ and/or high VL & $92 \%$ & 91 & $3.14(0.96-10.3)$ & $67 \%(0-90)$ \\
\hline Age $30+$ and/or high VL and/or AFSI $<16$ & $93 \%$ & 93 & $8.73(1.2-64.2)$ & $88 \%(13-98)$ \\
\hline
\end{tabular}


early age at first sexual intercourse are associated with an increased risk of high-grade CIN or cancer among HPV-positive women.

In this study, no association was observed between number of lifetime sexual partners and risk of highgrade CIN or cancer among HPV-positive women. This could be explained, in part, because most of the women in our study reported a low number of lifetime sexual partners. This finding, in conjunction with the significant association observed for AFSI, suggests that in Mexico, the age at which a woman begins to be sexually active may be as important as the total number of lifetime sexual partners. Women who began to have sexual intercourse before the age of 16 were found to have a two-fold higher risk of high-grade CIN and cervical cancer $(O R=2.17,95 \% C I=1.3-3.7)$ than women who had sexual intercourse for the first time after the age of 16 , after adjusting for age and viral load.

This increased risk could be due to the fact that AFSI may be a proxy for the time of first HPV infection. Women who had sexual intercourse for the first time at a younger age may have been exposed to a persistent HPV infection for a longer time than women who began to have sex at a later age. ${ }^{37}$ An exposure duration variable was created by substracting AFSI from current age to serve as a proxy for the amount of time a woman may have been potentially exposed to an HPV infection. After adjusting for age, this variable was significantly associated with an increased risk of high-grade CIN and cervical cancer; however, it was not significantly associated in the multivariate analysis.

Another explanation could be that women who begin to have sexual intercourse before the age of 16 are more vulnerable to HPV infection due to the fact that during puberty the cervix undergoes cellular changes at the transformation zone known as ectopy. ${ }^{38}$ During ectopy the cervix cells may not only be more susceptible to infection with HPV, they may also be prone to persistent HPV infection and to more lasting damage from an infection. ${ }^{39,40}$ This could explain the observed increased risk of high-grade CIN and cervical cancer among the study participants who began to have sexual intercourse before the age of 16 .

Our findings did not substantiate those of other studies that observed an association between number of pregnancies, number of live births, and risk of high-grade CIN and cancer. ${ }^{28}$ Age-adjusted analyses indicated significant associations between number of pregnancies, number of live births and risk of disease. However, these associations were not significant in the multivariate analyses. There are conflicting results concerning the use of oral contraceptives and risk of high-grade CIN and cervical cancer. ${ }^{27,28,41}$ This study did not find an association between use of hormonal contraception and risk of developing disease. The lack of association may be explained by the fact that most studies report an increased risk of high-grade CIN and cancer among long-term users of oral contraceptives. Less than $8 \%$ of the Morelos HPV Study participants reported using a hormonal contraceptive method for a period of five years or more. Smoking has also been associated with an increased risk of high-grade CIN and cancer in several studies. ${ }^{42,43}$ The lack of association between smoking and risk of cervical cancer in this study may be due to the fact that only $11 \%$ of the respondents reported having smoked for more than ten years, and 22\% reported having ever smoked.

A significant limitation of this study is the use of the HC 2 test to infer viral load associations with high-grade $\mathrm{CIN}$ and cancer. Gravitt et al found that cumulative viral load measurements by HC 2 may overestimate type-specific viral load. ${ }^{44}$ One of the most important strengths of this study is the use of HPV-positive cases and controls. By comparing HPV-positive cases to HPV-positive controls we were able to examine the associations between different variables and high-grade CIN and cancer, while accounting for any confounding by HPV.

Identifying the factors that contribute to the development of cervical cancer after HPV infection is very important because most women who receive a positive HPV test result do not go on to develop disease. The results from this study indicate that certain factors, such as increasing age, high viral load, a young age at first sexual intercourse, and low SES are associated with an increased risk of developing high-grade CIN and cervical cancer among high-risk HPV-positive women. This information could be used to prioritize limited screening and treatment services to women who have specific characteristics that may put them at an increased risk of disease. Additionally, by identifying which women have a lower risk of disease it may be possible to reduce the number of unnecessary colposcopies. These results could have important implications for future screening activities for the prevention of cervical cancer in Mexico and other Latin American countries.

\section{Acknowledgements}

Financial support for this study was provided by the Instituto Mexicano del Seguro Social (IMSS), the Consejo Nacional para la Ciencia y Tecnología grant \# 26267M, Insituto Nacional de Salud Pública, the National Institutes of Health grant \# U19 AI38533, and Digene Corporation. 


\section{References}

I. Arrossi S, Sankaranarayanan R, Parkin DM. Incidence and mortality of cervical cancer in Latin America. Salud Publica Mex 2003;45:306-314. 2. Bosch FX, Lörincz A, Muñoz N, Meijer CJ, Shah KV. The causal relation between human papillomavirus and cervical cancer. J Clin Pathol 2002;55:244-265.

3. Muñoz N, Bosch FX, de Sanjose S, et al. Epidemiologic classification of human papillomavirus types associated with cervical cancer. N Engl J Med 2003;348:518-527.

4. Bosch FX, de Sanjose S. Chapter I: Human papillomavirus and cervical cancer--burden and assessment of causality. J Natl Cancer Inst Monogr 2003;31:3-13

5. Muñoz N, Bosch FX, Castellsague X, et al. Against which human papillomavirus types shall we vaccinate and screen? The international perspective. Int ] Cancer 2004; | | : 278-285.

6. Flores Y, Shah K, Lazcano E, Hernandez M, Bishai D, Ferris DG, Lorincz A, Hernandez P, Salmeron J; Morelos HPV Study Collaborators. Design and methods of the evaluation of an HPV-based cervical cancer screening strategy in Mexico:The Morelos HPV Study. Salud Publica Mex 2002;44(4):335-344.

7. Salmeron J, Lazcano-Ponce E, Lorincz A, Hernandez M, Hernandez P, Leyva A, Uribe M, Manzanares H, Antunez A, Carmona E, Ronnett BM, Sherman ME, Bishai D, Ferris D, Flores Y, Yunes E, Shah KV. Comparison of HPV-based assays with Papanicolaou smears for cervical cancer screening in Morelos State, Mexico. Cancer Causes Control 2003; I 4(6):505-5I2. 8. Collins SI, Mazloomzadeh S, Winter H, et al. Proximity of first intercourse to menarche and the risk of human papillomavirus infection: a longitudinal study. Int | Cancer 2005; | 14:498-500.

9. Ho GY, Bierman R, Beardsley L, Chang CJ, Burk RD. Natural history of cervicovaginal papillomavirus infection in young women. $N$ Engl J Med 1998;338:423-428.

10. Herrero R, Castle PE, Schiffman M, et al. Epidemiologic profile of type-specific human papillomavirus infection and cervical neoplasia in Guanacaste, Costa Rica.J Infect Dis 2005; 191:1796-1807.

II. Hernandez-Giron C, Smith JS, Lörincz A, Lazcano E, Hernandez-Avila M, Salmeron J. High-Risk Human Papillomavirus Detection and Related Risk Factors Among Pregnant and Nonpregnant Women in Mexico. Sex Transm Dis 2005;32:613-618.

12. Smith JS, Green J, Berrington de Gonzalez A, et al. Cervical cancer and use of hormonal contraceptives: a systematic review. Lancet 2003;361:1159-1167.

13. Muñoz N, Castellsague X, de Gonzalez AB, Gissmann L. Chapter I: HPV in the etiology of human cancer. Vaccine 2006;24S3:SI-SIO. 14. Smith EM, Johnson SR, Figueres EJ, et al. The frequency of human papillomavirus detection in postmenopausal women on hormonal replacement therapy. Gynecol Oncology 1997;65:44I-446. 15. Plummer M, Herrero R, Franceschi S et al. Smoking and cervical cancer: pooled analysis of the IARC multi-centric case--control study. Cancer Causes Control 2003;14:805-814.

16. Castellsague X, Muñoz N. Chapter 3: Cofactors in human papillomavirus carcinogenesis--role of parity, oral contraceptives, and tobacco smoking. J Natl Cancer Inst Monogr 2003;31:20-28. 17. Carcinoma of the cervix and tobacco smoking: Collaborative reanalysis of individual data on 13,54I women with carcinoma of the cervix and 23,017 women without carcinoma of the cervix from 23 epidemiological studies. Int J Cancer 2006; I 8: 148I-1495. 18. de Sanjose S, Bosch FX, Muñoz N, Shah K. Social differences in sexual behaviour and cervical cáncer. IARC Sci Publ 1997;138:309-3I7.
19. Hernández Avila M, Lazcano Ponce EC, Alonso de Ruíz P, Romieu I. Evaluation of the cervical cancer screening program in Mexico:A population-based case-control study. Int J Epidemiol 1998;27:I-7. 20. Josefsson AM, Magnusson PK, Ylitalo N, et al.Viral load of human papillomavirus 16 as a deteminant for development of cervical cancer in situ: a nested case-control study. Lancet 2000;355:2189-2193. 21. Hernandez-Hernandez DM, Ornelas-Bernal L, Guido-Jimenez M, et al. Association between high-risk human papillomavirus DNA load and precursor lesions of cervical cancer in Mexican women. Gynecol Oncol 2003;90:310-317.

22. Moberg M, Gustavsson I,Wilander E, Gyllensten U. High viral loads of human papillomavirus predict risk of invasive cervical carcinoma. $\mathrm{Br}$ J Cancer 2005; 92:891-894.

23. Schlecht NF, Trevisan A, Duarte-Franco E, et al. Viral load as a predictor of the risk of cervical intraepithelial neoplasia. Int J Cancer 2003; 103: 519-524.

24. Lörincz AT, Castle PE, Sherman ME, et al. Viral load of human papillomavirus and risk of CIN3 or cervical cancer. Lancet 2002;360: 228-229.

25. Castle PE, Schiffman M, Scott DR, et al. Semiquantitative human papillomavirus type 16 viral load and the prospective risk of cervical precancer and cancer. Cancer Epidemiol Biomarkers Prev 2005; |4: I3 I I$13 \mid 4$.

26. Shields TS, Brinton LA, Burk RD, et al. A Case-Control Study of Risk Factors for Invasive Cervical Cancer among U.S. Women Exposed to Oncogenic Types of Human Papillomavirus. Cancer Epidemiol Biomarkers Prev 2004; I3:1574-I582.

27. Franceschi S. The IARC commitment to cancer prevention: the example of papillomavirus and cervical cancer. Recent Results Cancer Res 2005; 166:277-297.

28. Hildesheim A, Herrero R, Castle PE, et al. HPV co-factors related to the development of cervical cancer: Results from a population-based study in Costa Rica. Br J Cancer 2001;84:1219-1226.

29. Schiffman M, Castle PE. The promise of global cervical-cancer prevention. N Engl J Med 2005;353:2101-2104.

30. Last J A. Dictionary of Epidemiology. Fourth Edition. Oxford University Press, New York. 200I.

31. Schiffman M, Castle PE, Jeronimo J, Rodriguez AC, Wacholder S. Human papillomavirus and cervical cancer. Lancet 2007;370(9590):890-907. 32. Kahn JA, Lan D, Kahn RS. Sociodemographic factors associated with high-risk human papillomavirus infection. Obstet Gynecol. 2007; I IO(I):87-95.

33. Akers AY, Newmann SJ, Smith JS. Factors underlying disparities in cervical cancer incidence, screening, and treatment in the United States. Curr Probl Cancer. 2007;3I(3):I57-I8I.

34. Schiffman M, Brinton L, Devesa S, Fraumeni J. Cervical cancer. In Cancer Epidemiology and Prevention, 2nd edition. Schottenfeld D, Fraumen JF, eds. Oxford University Press, New York. 1996. 35. Gravitt PE, Kovacic MB, Herrero R, Schiffman M, Bratti C, Hildesheim A, Morales J,Alfaro M, Sherman ME, Wacholder S, Rodriguez AC, Burk RD. High load for most high risk human papillomavirus genotypes is associated with prevalent cervical cancer precursors but only HPVI6 load predicts the development of incident disease. Int J Cancer. 2007 Aug 23; [Epub ahead of print]

36. Dalstein V, Riethmuller D, Prétet JL, Le Bail Carval K, Sautière JL, Carbillet JP, Kantelip B, Schaal JP, Mougin C. Persistence and load of highrisk HPV are predictors for development of high-grade cervical lesions: a longitudinal French cohort study. Int J Cancer 2003; 106(3):396-403. 37. Deacon JM, Evans CD, Yule R, et al. Sexual behaviour and smoking as determinants of cervical HPV infection and of CIN3 among those 
infected: a case-control study nested within the Manchester cohort. $\mathrm{Br}$ J Cancer 2000; 83: I565-I572.

38. Harris RWC, Briton LA, Cowdell RH, et al. Characteristics of women with dysplasia or carcinoma in situ of the cervix uteri. $\mathrm{Br}$ J Cancer 1980;42:359-369.

39. Castle PE, Jeronimo J, Schiffman M, Herrero R, Rodriguez AC, Bratti MC, Hildesheim A, Wacholder S, Long LR, Neve L, Pfeiffer R, Burk RD.

Age-related changes of the cervix influence human papillomavirus type distribution. Cancer Res. 2006;66(2): I 218-1224.

40. Rocha-Zavaleta L, Yescas G, Cruz RM, Cruz-Talonia F. Human papillomavirus infection and cervical ectopy. Int J Gynaecol Obstet. 2004;85(3):259-266.
4I. La Vecchia C, Altieri A, Franceschi S, Tavani A. Oral contraceptives and cancer: an update. Drug Saf 200I;24:74I-754.

42. Plummer M, Herrero R, Franceschi S, et al. Smoking and cervical cancer: pooled analysis of the IARC multi-centric case--control study. Cancer Causes Control 2003;|4:805-8I4.

43. Santos C, Muñoz N, Klug S, et al. HPV types and cofactors causing cervical cancer in Peru. Br J Cancer 2001;85:966-97I.

44. Gravitt PE, Burk RD, Lörincz A, et al. A comparison between real-time polymerase chain reaction and hybrid capture 2 for human papillomavirus DNA quantitation. Cancer Epidemiol Biomarkers Prev 2003;12:477-484. 